\title{
Does an Authoritative Parenting Style Associate with Secure Attachment to Father?
}

\author{
Received April 27, 2020 | Accepted June 26, 2020
}

Fatmawati*

fatmawati@ar-raniry.ac.id
Siti Maryam

sitimaryam@unsyiah.ac.id

UIN Ar-Raniry-Banda Aceh

\begin{abstract}
Good parenting produces a good mutual relationship between parent and child. Fathers have a role in parenting. A father is involved in nurturing by interacting with children and utilizing his resources, including physical, cognition, and affection. To that end, this study aimed to investigate the relationship between authoritative parenting and secure attachment to fathers among adolescents in Pidie-Aceh, Indonesia. This study used a purposive sampling technique with a total sample of 200 teenagers. Data collection techniques were performed by using authoritative parenting scale and secure attachment to father scale. The Pearson correlation test results showed that authoritative parenting was positively related to secure attachment to father. The analysis proved that authoritative parenting was significantly related to adolescents' attachment to their fathers
\end{abstract}

Keywords: authoritative parenting, secure attachment, father, adolescent.

\section{INTRODUCTION}

Traditionally, in a complete family a mother has a role as primary caregiver and father as the breadwinner (Duncan, Schmitt, \& Vandell, 2019). The culture in Asia, including Indonesia, strictly separates the role of fathers and mothers inside and outside the home (Wagani, 2018). Fathers are more outside to make a living and are responsible as the head of the family, while the mothers are at home to take care of the family. Simonelli, Parolin, Sacchi, De Palo, and Vieno (2016) stated that the role of fathers is often identical as someone who looks after and protects the family to feel safe and comfortable. Along with changes that occur in society, the father is an important figure in the development of children (Gordon, 2016; Meuwissen \& Carlson, 2018), especially when the adolescents are within the family. This indicates that not only mother, but father also plays an important role for taking care of his family.

Adolescence is a period of significant changes in attachment relations (Pace, Di Folco, \& Guerriero, 2018; Theisen, Fraley, Hankin, Young, \& Chopik, 2018). In adolescence, the relationship between parents and teenagers creates mutual dependence that lasts for a long time (de Vries, Hoeve, Stams, \& Asscher, 2016). Interaction with parents is formed through their cognitive and behavior since they were children, which then preparing them to interact with other people outside the family (Oldfield, Humphrey, \& Hebron, 2016; Koehn \& Kerns, 2018). Besides, this bond of warm, deep, and quality relationships is able to help adolescents in dealing with the changes that occur within themselves (Jones et al., 2018). For that, attachment in adolescence is needed to help them deal with the wider environment 
Adolescents' attachment relationships are formed in order to meet their physical and emotional needs (Tu, Marks, \& El-Sheikh, 2017). Teenage boys are more enjoy and satisfied when engaging in activities with fathers than mothers (Fuertes, Faria, Beeghly, \& Lopes-dos-Santos, 2016). Kerstis, Åslund, and Sonnby (2018) showed that adolescents who had an intensive communication with their fathers, had great freedom to find their own identity and looked for their own abilities. Conversations with fathers who are attentive and intimate can support the social growth of adolescents (Psychogiou et al., 2019).

Furthermore, teenagers who are securely attached to fathers have a very high ability to empathize, and are able to make adjustments (Stern \& Cassidy, 2018). This attachment can be used as a predictor for adolescents in establishing relationships with peers or relationships that will be established later with others (Jones et al., 2018). Lack of attachment to fathers in adolescent boys results in blurring of masculinity traits, where in adolescent girls result in loosening of sexual activity (van Polanen, Colonnesi, Fukkink, \& Tavecchio, 2017; Fernandes et al., 2018). Yoder, Leibowitz, and Peterson (2018) added that the lack of attachment to the fathers is a driving factor for children to commit crime. Those findings conclude that attachment with fathers has a very significant contribution for both male and female adolescents, especially in shaping their personality.

Attachment is one component in the relationship between parent and child, which is formed from parenting styles (Ebrahimi, Amiri, Mohamadlou, \& Rezapur, 2017). Lomanowska, Boivin, Hertzman, and Fleming (2017) described parenting as an interaction between children and parents during parenting activities, where each style tends to have a different effect on the child's personality. Good parenting style produces a good mutual relationship between parent and child (Feldman \& Bakermans-Kranenburg 2017). Nevertheless, the family can also be a source of threat for the child, because of the mistreatments that are often received from the family, especially parents (Dix \& Moed, 2019). Authoritative parenting is one of parenting styles characterized by high responsiveness and high demands (Darling \& Steinberg, 2017). Authoritative parents are responsive to the child's emotional needs while having high standards. They set limits and are very consistent in enforcing boundaries. Fathers who perform authoritative parenting are warm, attuned, and nurturing (Lau \& Power, 2019).

Aceh Province is one of provinces in Indonesia, geographically located in the westernmost region of Sumatra Island. As part of the territory of the Republic of Indonesia, Aceh is a province that currently has 23 districts/cities, one of which is Pidie. In Pidie, the kinship system is a very important part of the social structure. According to sociology-anthropology studies, the Pidie community adheres to a patrilineal kinship group system, a kinship group whose authority is on the side of the father (male) (Agnes, 2011). For this reason, parenting style applied by the father has a very big influence on the child's development. This region specificity has also differentiated this study from previous research.

Based on the description above, this paper aimed to examine the relationship between authoritative parenting and secure attachment with fathers among adolescents in Pidie. The hypothesis was that authoritative parenting is positively and significantly related to adolescents' secure attachment to father.

\section{METHODS}

This study used quantitative method. Respondents recruited were 200. In order to be eligible to participate, the respondents must between 12 to 18 years old and still have 
father. Within this study, authoritative parenting is defined as the style of parenting in which fathers can prioritize the interests of adolescents and controls them with rule The fathers are not only rational and realistic about adolescents' abilities, but also have a warm, caring, and sensitive to the needs of children. Whereas, secure attachment to fathers is a form of emotional bonding between fathers and adolescents with good communication and high interpersonal trust.

For measuring authoritative parenting and secure attachment to fathers, two different scales were used. The authoritative parenting scale was developed based on the theory from Baumrind (1967) which consisted of 16 items (7 favorable items and 9 unfavorable items) with a reliability of 0.768 . While secure attachment to father scale was developed based on the theory from Bartholomew and Horowitz (in Baron \& Bryne, 2005) which had 13 items ( 7 items were favorable and 6 items were unfavorable) with a reliability of 0.728 . Both scale used a Likert scaling model.

After all data from both scales were obtained, then Pearson Correlation analysis was performed as a hypothesis test through the SPSS for Windows version 20.0. This was implemented to test the relationship between authoritative parenting and secure attachment to fathers.

\section{RESULTS}

The table 1 below is presented in order to describe a general picture of authoritative parenting and secure attachment to fathers among adolescents in Pidie.

Table 1. Description of Authoritative Parenting and Secure Attachment to Fathers

\begin{tabular}{ccccccccc}
\hline Variable & \multicolumn{3}{c}{ Hypothetical Data } & \multicolumn{5}{c}{ Empirical Data } \\
\cline { 2 - 10 } & Xmax & min & Iean & D & Imax & min & Iean & D \\
\hline Authoritative Parenting & 64 & 16 & 40 & & 61 & 16 & 9.04 & 23 \\
\hline Secure Attachment & 52 & 13 & 12.5 & 5 & 50 & 25 & 8.96 & 11 \\
\hline
\end{tabular}

Based on the statistical analysis, hypothetical data showed that authoritative parenting had a minimum number of answer (Xmin) of 16, a maximum answer (Xmax) of 64 , a mean value of 40 , and a standard deviation (SD) of 8 , where empirically, the minimum answer (Xmin) was 16, the maximum answer (Xmax) was 61, the mean value was 49.04, and standard deviation (SD) was 6.23.

Furthermore, from statistical analysis, it was found that hypothetical data of secure attachment to fathers, were: a minimum number of answer (Xmin) was 13, a maximum answer (Xmax) was 52, a mean value was 32.5, and a standard deviation (SD) was 6.5, where empirically, the minimum answer (Xmin) was 25, the maximum answer (Xmax) was 50, the mean value was 38.96, and standard deviation (SD) was 5.11.

After obtaining the results from empirical analysis, the categories of each variable then could be set, as follows.

Table 2. Categorization of Authoritative Parenting and Secure Attachment to Fathers

\begin{tabular}{ccccc}
\hline \multicolumn{1}{c}{ Category } & Formula & Interval & $\begin{array}{c}\text { Frequency } \\
(\mathbf{n})\end{array}$ & $\begin{array}{c}\text { Percentage } \\
(\%)\end{array}$ \\
\hline 1. Authoritative & Parenting & & & \\
\hline Low & $\mathrm{X}<\mathrm{M}-1,0 \mathrm{SD}$ & $\mathrm{X}<43$ & 27 & 13.5 \\
\hline Middle & $\mathrm{M}-1,0 \mathrm{SD} \leq \mathrm{X}<\mathrm{M}+1,0 \mathrm{SD}$ & $43 \leq \mathrm{X}<55$ & 139 & 69.5 \\
\hline High & $\mathrm{M}+1,0 \mathrm{SD} \leq \mathrm{X}$ & $55 \leq \mathrm{X}$ & 34 & 17.0 \\
\hline
\end{tabular}




\begin{tabular}{ccccc} 
Category & Formula & Interval & $\begin{array}{c}\text { Frequency } \\
(\mathbf{n})\end{array}$ & $\begin{array}{c}\text { Percentage } \\
(\boldsymbol{\%})\end{array}$ \\
\hline 2. Secure Attachment to Fathers & & & \\
Low & $\mathrm{X}<\mathrm{M}-1,0 \mathrm{SD}$ & $\mathrm{X}<34$ & 29 & 14.5 \\
Middle & $\mathrm{M}-1,0 \mathrm{SD} \leq \mathrm{X}<\mathrm{M}+1,0 \mathrm{SD}$ & $34 \leq \mathrm{X}<44$ & 133 & 66.5 \\
High & $\mathrm{M}+1,0 \mathrm{SD} \leq \mathrm{X}$ & $44 \leq \mathrm{X}$ & 38 & 19.0 \\
\hline
\end{tabular}

Based on the table above, it could be seen that as many as $13.5 \%$ (27 people) had a low authoritative parenting category, 69.5\% (139 people) had a moderate authoritative parenting category, and $17.0 \%$ (34 people) had a high authoritative parenting category. In addition, table above also described that as many as $14.5 \%$ (29 people) had a low category of secure attachment to fathers, $66.5 \%$ (133 people) had a category of moderate secure attachment to fathers, and $19.0 \%$ (38 people) have a category of high secure attachment to fathers.

Next, before the hypothesis test was carried out, the test for the normality and linearity were first performed as the prerequisite tests. Based on the results of normality test, the data distribution of authoritative parenting was normal K-S Z $=1,261$, with $\mathrm{p}=$ 0.083 ( $>>0.05$ ). Likewise with the secure attachment to fathers, the data is also normally distributed $\mathrm{K}-\mathrm{S} \mathrm{Z}=1,427$, with $\mathrm{p}=0.054(\mathrm{p}>0.05)$. Because these variables were normally distributed, the results of the study could be generalized to the study population. Furthermore, based on the results of the $\mathrm{F}$ deviation from linearity, obtained $\mathrm{F}=1,157$ with $p=0.288$ ( $p>0.05)$, it could be concluded that there was a linear relationship between authoritative parenting and secure attachment to fathers among adolescents.

After the fulfillment of the two prerequisites above, the next step was to test the hypothesis using Pearson correlation analysis. Based on the analysis, it was found that correlation coefficient between authoritative parenting and secure attachment to fathers was 0.407 with $p=0.000$ ( $p>0.05$ ). The correlation coefficient obtained was positive, so it could be interpreted that authoritative parenting was positively and significantly related to secure attachment to fathers among adolescents (hypothesis accepted.

\section{DISCUSSIONS}

The results of data analysis signified that the hypothesis in this study was accepted. The relationship between authoritative parenting and secure attachment to fathers proved to be significant. The results showed that authoritative parenting was positively related to secure attachment to fathers.

Attachment is one component in the relationship between parent and child, which is formed from parenting styles (Ebrahimi, Amiri, Mohamadlou, \& Rezapur, 2017). Safdar and Zahrah (2016) stated that parents with proper parenting style foster a secure attachment and it may increase the quality of care itself. Quality factors of care include the sensitivity of parents to respond consistently, precisely, and full of warmth (Katz, Lemish, Cohen, \& Arden, 2019).

This finding was relevant with some previous studies. Mirderikvand, Sami, Mohammadi, Ahmadi, and Taheri (2016) stated that parents who applied authoritative parenting could foster a secure attachment. Nunes and Mota (2017) also added the importance of authoritative parenting style to assist the quality development of parents' attachment. This indicated that parents-especially fathers, who adopt authoritative parenting will help them to build a good attachment with their children. 
In another study conducted by Safdar and Zahrah (2016) mentioned that parenting styles became a strong predictor for attachment, where authoritative parenting had a positive impact in creating a secure attachment with adolescents. Besides, Wasarhelyi, John, Long, and Lovas (2019) also said that authoritative fathering had a good contribution on decision-making ability among adolescents.

Based on the above research findings, this study provided several implications, namely: (1) Parent attachment to children needs to be formed as early as possible through the implementation of appropriate parenting style; (2) Lack of flexibility of most fathers can result in maladaptive behavior in adolescents, including juvenile delinquency, drug abuse, free sex, or depression; and (3) Appropriate parenting can be obtained by understanding parents respective roles in building a family.

Nevertheless, this study also had some limitations. Among them was the use of variables that only consisted of parenting and attachment. In addition, the number of respondents recruited did not vary so the results obtained were not so comprehensive. Lastly, the research method only used quantitative research techniques so that the dynamics of parenting and attachment to fathers were not reflected in detail.

\section{CONCLUSIONS}

Based on the analysis, the results showed that authoritative parenting was positively related to secure attachment to father. As Pidie community adheres to a patrilineal kinship group system, the authoritative parenting style amongst fathers should be maintained in order to build a secure attachment with their children, especially adolescents.

Through the discussions above, the authors provided several suggestions. In order to enrich the results and also the analysis, it is better to add qualitative data. In addition, increasing the number of respondents can also be done to improve the validity and reliability of research results.

\section{REFERENCES}

Baron, R. A. \& Bryne, D. (2005). Psikologi Sosial (10 ${ }^{\text {th }}$ ed.). Jakarta: Erlangga.

Baumrind, D. (1967). Child care practices anteceding three patterns of preschool behavior. Genetic Psychology Monographs.

Darling, N., \& Steinberg, L. (2017). Parenting style as context: An integrative model. In Interpersonal development (pp. 161-170). Routledge.

de Vries, S. L., Hoeve, M., Stams, G. J. J., \& Asscher, J. J. (2016). Adolescent-parent attachment and externalizing behavior: The mediating role of individual and social factors. Journal of Abnormal Child Psychology, 44(2), 283-294.

Dix, T., \& Moed, A. (2019). Parenting and depression. In Handbook of parenting (pp. 449-482). Routledge.

Duncan, R. J., Schmitt, S. A., \& Vandell, D. L. (2019). Additive and synergistic relations of early mother-child and caregiver-child interactions for predicting later achievement. Developmental Psychology, 55(12), 2522.

Ebrahimi, L., Amiri, M., Mohamadlou, M., \& Rezapur, R. (2017). Attachment styles, parenting styles, and depression. International Journal of Mental Health and Addiction, 15(5), 1064-1068.

Feldman, R., \& Bakermans-Kranenburg, M. J. (2017). Oxytocin: A parenting hormone. Current Opinion in Psychology, 15, 13-18.

Fernandes, C., Veríssimo, M., Monteiro, L., Antunes, M., Vaughn, B. E., \& Santos, A. J. (2018). Mothers, fathers, sons, and daughters: Are there sex differences in the 
organization of secure base behavior during early childhood. Infant Behavior and Development, 50, 213-223.

Fuertes, M., Faria, A., Beeghly, M., \& Lopes-dos-Santos, P. (2016). The effects of parental sensitivity and involvement in caregiving on mother-infant and fatherinfant attachment in a Portuguese sample. Journal of Family Psychology, 30(1), 147.

Gordon, M. S. (2016). Community disadvantage and adolescent's academic achievement: The mediating role of father influence. Journal of Child and Family Studies, 25(7), 2069-2078. Jones, J. D., Fraley, R. C., Ehrlich, K. B., Stern, J. A., Lejuez, C. W., Shaver, P. R., \& Cassidy, J. (2018). Stability of attachment style in adolescence: An empirical test of alternative developmental processes. Child development, 89(3), 871-880.

Katz, I., Lemish, D., Cohen, R., \& Arden, A. (2019). When parents are inconsistent: Parenting style and adolescents' involvement in cyberbullying. Journal of Adolescence, 74, 1-12.

Kerstis, B., Åslund, C., \& Sonnby, K. (2018). More secure attachment to the father and the mother is associated with fewer depressive symptoms in adolescents. Upsala Journal of Medical Sciences, 123(1), 62-67.

Koehn, A. J., \& Kerns, K. A. (2018). Parent-child attachment: Meta-analysis of associations with parenting behaviors in middle childhood and adolescence. Attachment \& Human Development, 20(4), 378-405.

Lau, E. Y. H., \& Power, T. G. (2019). Coparenting, parenting stress, and authoritative parenting among Hong Kong Chinese mothers and fathers. Parenting, 1-10.

Lomanowska, A. M., Boivin, M., Hertzman, C., \& Fleming, A. S. (2017). Parenting begets parenting: A neurobiological perspective on early adversity and the transmission of parenting styles across generations. Neuroscience, 342, 120-139.

Meuwissen, A. S., \& Carlson, S. M. (2018). The role of father parenting in children's school readiness: A longitudinal follow-up. Journal of Family Psychology, 32(5), 588.

Mirderikvand, F., Sami, A., Mohammadi, A. A., Ahmadi, M., \& Taheri, M. (2016). Predicting the Parenting Styles Based on Attachment Styles and Emotional Intelligence. Journal of Health and Care, 18(2), 120-130.

Nunes, F., \& Mota, C. P. (2017). Parenting styles and suicidal ideation in adolescents: Mediating effect of attachment. Journal of child and family studies, 26(3), 734-747.

Oldfield, J., Humphrey, N., \& Hebron, J. (2016). The role of parental and peer attachment relationships and school connectedness in predicting adolescent mental health outcomes. Child and Adolescent Mental Health, 21(1), 21-29.

Pace, C. S., Di Folco, S., \& Guerriero, V. (2018). Late-adoptions in adolescence: Can attachment and emotion regulation influence behaviour problems? A controlled study using a moderation approach. Clinical Psychology \& Psychotherapy, 25(2), 250-262.

Psychogiou, L., Nath, S., Kallitsoglou, A., Dimatis, K., Parry, E., Russell, A. E., ... \& Moberly, N. J. (2018). Children's emotion understanding in relation to attachment to mother and father. British Journal of Developmental Psychology, 36(4), 557-572.

Safdar, S., \& Zahrah, S. M. (2016). Impact of parenting styles on the intensity of parental and peer attachment: Exploring the gender differences in adolescents. American Journal of Applied Psychology, 4(2), 23-30.

Simonelli, A., Parolin, M., Sacchi, C., De Palo, F., \& Vieno, A. (2016). The role of father involvement and marital satisfaction in the development of family interactive abilities: a multilevel approach. Frontiers in Psychology, 7, 1725. 
Stern, J. A., \& Cassidy, J. (2018). Empathy from infancy to adolescence: An attachment perspective on the development of individual differences. Developmental Review, 47, $1-22$.

Theisen, J. C., Fraley, R. C., Hankin, B. L., Young, J. F., \& Chopik, W. J. (2018). How do attachment styles change from childhood through adolescence? Findings from an accelerated longitudinal Cohort study. Journal of Research in Personality, 74, 141146. Tu, K. M., Marks, B. T., \& El-Sheikh, M. (2017). Sleep and mental health: the moderating role of perceived adolescent-parent attachment. Sleep Health, 3(2), 9097.

Van Polanen, M., Colonnesi, C., Fukkink, R. G., \& Tavecchio, L. W. (2017). Is Caregiver Gender Important for Boys and Girls? Gender-Specific Child-Caregiver Interactions and Attachment Relationships. Early Education and Development, 28(5), 559-571.

Wagani, R. (2018). Role of Father versus Mother in self-esteem of Adolescence. Journal of Psychosocial Research, 13(2), 173-182.

Wasarhelyi, J. N., John, B., Long, B., \& Lovas, G. S. (2019). The Effects of Parent Attachment and Parenting Styles on Decision-Making in College Students [Susquehanna University]. Journal of Student Research.

Yoder, J. R., Leibowitz, G. S., \& Peterson, L. (2018). Parental and peer attachment characteristics: Differentiating between youth sexual and non-sexual offenders and associations with sexual.Journal of Interpersonal Violence, 33(17), 2643-2663. 